\title{
Digital Wellbeing for All: Expanding Inclusivity to Embrace Diversity in Socio-Emotional Status
}

\author{
Reem S. Al-Mansoori \\ College of Science and \\ Engineering \\ Hamad Bin Khalifa University \\ Doha, Qatar \\ reem.almansoori.qtr@gmail.com \\ Raian Ali \\ College of Science and Engineering \\ Hamad Bin Khalifa University \\ Doha, Qatar \\ raali2@hbku.edu.qa
}

\author{
Mohammad Naiseh \\ School of Electronics \\ and Computer Science \\ University of Southampton \\ Southampton, UK \\ m.naiseh@soton.ac.uk
}

\author{
Dena Al-Thani \\ College of Science and \\ Engineering \\ Hamad Bin Khalifa University \\ Doha, Qatar \\ dalthani@hbku.edu.qa
}

\begin{abstract}
The ubiquity of information and communication technology contributed positively in enhancing lives, mainly in increasing productivity and economic growth, while their impact on life satisfaction and wellbeing has been a hidden cost. Digital media shall empower users to maximise their digital wellbeing, i.e. healthy and regulated relationship with technology. Similar to usability, people differ in their needs to achieve and maintain their digital wellbeing. A technology design shall be inclusive in how it helps users to increase their digital wellbeing and reduce possible harm. Typical inclusivity dimensions in Human-Computer Interaction research include gender, race, physical and cognitive abilities, with the aim of making the product usable by the wider possible user set. However, another range of inclusivity dimensions becomes prominent and that is the diversity in users' socio-emotional characteristics such as susceptibility to online pressure (technical and social), resilience and others. Such characteristics can be traits, e.g. introversion, or temporal status, e.g. being in a low mood. In this position paper, we are proposing digital wellbeing as a target for an inclusive design where technology designers need to anticipate and reduce the negative impact of their products and services on the wellbeing of users through considering their diverse socio-emotional status.
\end{abstract}

Keywords: Human-Computer Interaction, inclusivity, digital wellbeing.

\section{INTRODUCTION}

As technology permeates every aspect of our daily lives, having technology that is useful, inclusive and safe is essential. In Human-Computer Interaction $(\mathrm{HCl})$, the relationship between humans and digital products has evolved from a desire for instant and intuitive screen interaction to one where such ubiquity and speed started to impact humans' wellbeing (Verbeek, 2005).

As information and communication technology (ICT) outputs occur at a rapid pace, it is difficult to predict innovation outcomes in this area compared to other areas of science. Software may be released to the users and 'go viral', causing tremendous effects on individuals' activities and societies' structures that have not been anticipated by their designers (Jirotka et al., 2017). In the case of social media, for instance, a number of studies showed the negative impacts on users' mental health correlated with the use of social media problematic usage (Wright et al., 2018, Marino et al., 2018). To support more balanced relationship with technology and help users' mental health and wellbeing, companies started to launch dedicated toolkits such as Google's Digital Wellbeing (https://wellbeing.google/). These toolkits cover basic wellbeing properties, e.g. minimising distraction, pausing and night mode for quality sleep. For this reason, and to minimise possible mental and cognitive costs triggered by certain interactive design features, digital platforms, services and devices need to anticipate the impact on users' wellbeing and increase digital wellness to the wider possible set of users and context of use. 
In this position paper, we discuss the need for digital wellbeing services and toolkits to be inclusive and sensitive to the diversity in the socioemotional characteristics of users, whether traits or temporal and contextual. Our definition of socialemotional status is based on the work of Halberstadt et al., 2011 and the attributes contributing to it proposed in (Parhomenko, 2014). In this context, we identify socio-emotional status as the degree to which an individual is able to practice conscious behaviour regulation, build harmonious relationships and be engaged in social activities. Being socio-emotional competent represents possessing the abilities to be selfaware, empathetic, motivated (to be involved even when facing difficulties or failures), self-regulated (having conscious self-control over emotions) with social knowledge and competencies to build and maintain healthy relationships (Parhomenko, 2014).

We provide a background on digital wellbeing and inclusive design, in addition to the paper's motivation in Section 2. Taking social media as an exemplar, we explain how popular design features lack sensitivity to users' diversity in their socioemotional status in Section 3. We discuss our proposal and its significance in Section 4 and we present challenges and future work directions in Section 5.

\section{BACKGROUND AND MOTIVATION}

Digital wellbeing is defined, by Widdicks et al., 2017, as "a positive feeling associated with the use of technology, striven by maintaining a balance between our 'real' and 'online' lives". Although this notion is relatively new, a considerable body of research had provided a foundation for it. This includes works on positive technology (Riva et al., 2012), positive design (Desmet and Pohlmeyer, 2013), positive computing (Calvo and Peters, 2014), experience design (Hassenzahl, 2010) and the work on Motivation Engagement and Thriving User Experience (METUX) in (Peters et al., 2018). The design frameworks resulted from these efforts share the goal of satisfying a number of users' psychological needs, such as autonomy, selfawareness, gratitude and ultimately enhance their wellbeing.

Inclusive design is a "project that sets out to include significant sectors of society that are all too frequently ignored or overlooked" (Coleman et al., 2003). Morris (2003) and Coleman et al. (2003) emphasised that inclusive design should address the needs of the widest possible audience, irrespective of age or ability. Rossetti, on the other hand, defined universal design (a term equivalent to inclusive design and used mostly in the U.S and Japan) as "the good design", and provided seven guiding principles (Rossetti, 2006). Heylighen and Bianchin (2013) explored this perspective further and discussed how the characteristics of an inclusive design are similar to those of a "good design".

Inclusivity has been often seen as the design ability to cater to the common forms of disabilities, such as visual and hearing impairment and physical disabilities. Others approached inclusivity from other perspectives, such as "diversity dimensions" (Himmelsbach et al., 2019). Age, gender, ethnicity, physical and mental abilities were extensively examined in $\mathrm{HCl}$ literature responding to calls for diversity-sensitive research (Himmelsbach et al., 2019).

Inclusivity definitions and frameworks varied from being general (i.e. an enabler for the diverse users rather than an excluder (Gyi et al., 2000)), to having the focus on physical, sensory, cognitive abilities, or all (Persad et al., 2007; Keates, and Clarkson, 2003; Abascal and Azevedo, 2007), to being socially inclusive through addressing social differences, such as inequalities (classes) which affect the social and structural contexts of how people experience technology (Himmelsbach et al., 2019; Erete et al., 2018). The consideration of the socio-emotional status of the user is yet to be seen as an inclusivity factor.

In our proposal for an inclusive design with the target of safeguarding users' digital wellbeing, we suggest that the design shall provide measures to avoid users' negative feelings of exclusion, isolation, anxiety and fears. For the design to be inclusive, it shall consider the diversity in the socioemotional status. For example, in applying this vision to social media, a wellbeing-aware design shall be accountable to those prone to be overly influenced by peer pressure and lack self-esteem. Such a design can tailor content and offer services to configure and customize interfaces to avoid causing anxiety and sadness. Possible interventions include diversifying the content, reminding users of the nature of interactions in cyberspace, providing users with tools for empowered refusal should they wish to opt-out, issuing direct or subliminal messages to promote healthy usage, and others. Design frameworks for inclusive digital wellbeing should aid designers in knowing how the diversity in the socio-emotional status inter-relates with design options and the context of use, and how to mitigate the negative impact. 


\section{DESIGN FEATURES AND WELLBEING}

The challenges surrounding inclusive design remain in the fact that designers need generalization to make it a universal design, and at the same time, they need specifications to account for humans' individuality (Luck, 2018). Designing for an average user, which is an artificial construct, is necessarily exclusive as average can be claimed as 'statistical myth' (Rose, 2016). Algorithmic-based designs, for instance, are biased as they promote content based on techniques such as collaborative filtering. This content customising process can promote content that is popular and make other content less visible, hence, excluding its audience. Different people possess diverse characteristics and variable capabilities, therefor, designers need to anticipate users' lived experiences (Luck, 2018). If we design with an average user in mind, many users may need to adapt to the interface provided to them (Abascal and Azevedo, 2007). This will result in a number of users not being able to do so and facing feeling of exclusion, which will affect their wellbeing.

The notion of the average user becomes even more questionable when addressing the socio-emotional characteristics of users. Emotional wellbeing is part of digital wellbeing and has been identified as a fundamental indicator of the quality of life as per the World Health Organization (Coyle et al., 2012). In social media designs, taken as an exemplar in this paper, features such as emoticons (in Facebook) are among the reasons why some individuals may suffer from negative emotions such as jealousy, which, as a consequence, lead to reduced wellbeing (Hudson et al., 2015). When these features are used by individuals with low self-esteem and high susceptibility to social influence, negative emotions and psychological states are more likely to arise (Altuwairiqi et al., 2019a).

In certain situations, like being in a remote geographic area or in lockdown, e.g. those related to the current COVID-19 pandemic, social media become highly needed and extensively consumed for essential wellbeing needs such as relatedness and feeling secure and informed. It can help some groups of users to maintain connectivity with others and maintain resilience in days of isolation. Beyond connectedness, people seek acceptance. It is a human nature to seek social acceptance, which is one of the determinants of wellbeing (DeWall and Bushman, 2011). Online features such as Likes can help enhance or deteriorate individuals' wellbeing as users may overly rely on them as indicators of the extent to whether they are socially accepted. The opposite of social acceptance, rejection, on the other hand, can increase anxiety, anger, depression and jealousy (Leary, 2010), and diminish an individual's self-esteem (Williams et al., 2000). Moreover, rejection is said to increase selfish and aggressive behaviour, leading to mass violence (Leary et al., 2003). Conversely, engaging these individuals in social activities and offering a sense of acceptance showed to reduce their aggression (DeWall et al., 2010).

Interacting with others on social media provides a context where individuals are subject to forms of social evaluation threats, in which rejection is one of them (DeWall and Bushman, 2011). In the physical world, being exposed to negative external judgements by others can lead to releasing stress hormone cortisol (Dickerson and Kemeny, 2004) and stimulating the production of proinflammatory cytokines (Dickerson et al., 2009), which are negative biological responses affecting humans' wellbeing. Studies showed that individual factors contribute to heightened and diminished responses to social rejection, hence differ from one person to another (DeWall and Bushman, 2011). Rejection and social disapprovals showed high neural correlations among people with high rejection sensitivity (Burklund et al., 2007) and low selfesteem (Onoda et al., 2010). Although cyber behaviour is not necessarily analogous to that in the physical world and we still require more research to understand its nuances, studies are showing similarity, e.g. in the fear of ostracism (Vorderer and Schneider, 2017) and the neural impact of certain social media features, such as Likes, on users and their wellbeing (Sherman et al., 2016).

\section{INCLUSIVE DESIGN FOR WELLBEING}

Some might argue that individuals ought to manage their own traits, weaknesses, insecurities and anxieties through self-regulation. However, as the design can make the user experience more compelling (and sometimes addictive), it can also consider reducing the triggers that underpin compulsive behaviours (Churchill, 2020), such as fear of missing out (FoMO). FoMO is a type of addictive online behaviour and represents an overdependence on social media due to the fear of not seeing or reacting to online activities on time (Alutaybi et al., 2019). Digital addiction can lead to anxiety, interrupted sleep, lack of concentration and emotional control (Cham et al., 2019, Altuwairiqi et al., 2019b). As such, FoMO is an example of how the design, in a particular socio-emotional status and context of use, triggers negative feelings such as fear. At the same time, an inclusive design can provide design features such as an advanced version of the autoreply, status and filtering (Alutaybi et al., 2019) to empower those who may be overly susceptible to social pressure and lack impulse control. Digital wellbeing can be supported by software mediated countermeasures which target behaviours directly and indirectly. This includes using limits settings (Löchtefeld et al. 2013), or virtual reality (Park et al., 2016), where the former focuses on usage restriction rules and 
time, and the latter on pairing the addictive behaviour with irritating noise (or other features) to associate it with negative feelings, hence reduce excessive gameplay.

We hypothesise that for a design to be inclusively wellness-sensitive, it has to address three essential inclusivity parameters, which are: physical, cognitive and socio-emotional status (Figure 1). We advocate that digital media design should be inclusive not only in terms of being accessible and usable to all and in a wide variety of contexts but also in accommodating the diversity in the socio-emotional status of users as a requirement for wellbeing.

The base of this pyramid represents the first encounter between humans and computers through accessibility, where access to digital platforms and services is guaranteed for users and caters for their diverse physical and cognitive abilities (i.e., visual impairment and hearing loss). Then comes usability, where people can use a design product (or service) to achieve specified goals with effectiveness, efficiency and satisfaction in a specified context of use (ISO, 2009). On the top, and closer to the users' socio-emotional status, comes the user experience which considers the satisfaction of users' pragmatic and hedonic goals (Petrie and Bevan, 2009). Optimising users' performance and users' satisfaction by achieving goals (ISO, 2009) are considered parts of a successful user experience that aims to enhance users' wellbeing. Our suggestion is to go a step further to consider digital wellbeing and be inclusive in accommodating the variation in users' socioemotional status (permanent and situational). In this way, not only we design to enhance users' experience, but also we aim to protect their wellbeing and mental health when interacting with technology, e.g. by helping them balance between 'real' and 'online' lives, hence, safeguarding their wellbeing (Widdicks et al., 2017).

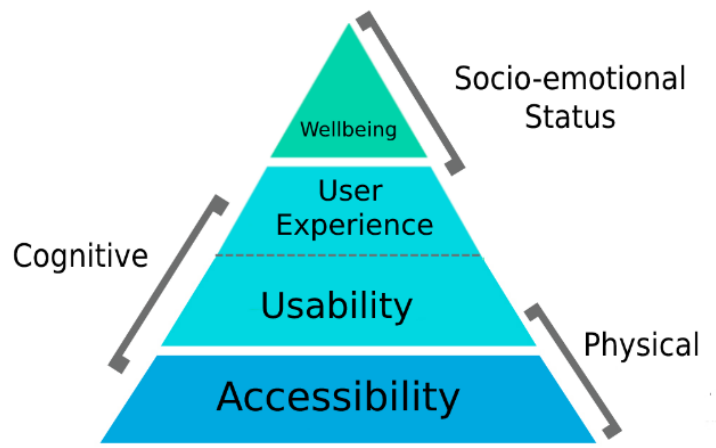

Figure 1: Inclusivity pyramid with wellbeing as a target

\section{CHALLENGES AND FUTURE RESEARCH OPPORTUNITIES}

Digital inclusion is not a straightforward topic. Perlgut, 2011, predicted that digital exclusion would be the major social justice challenge that would surpass all other social and economic determinants. The current work sheds light on inclusivity in its broader sense (beyond race, gender, physical and cognitive disabilities). This work suggests modifying inclusivity indicators to consider people's diverse socio-emotional status as an attempt to safeguard their wellbeing. To the best of our knowledge, this work is the first in proposing diversity in socio-emotional status as another parameter to inclusivity.

While inclusivity (considering socio-emotional status) with the aim of increasing digital wellbeing is a desirable design goal, a number of challenges are to address. The decision on the requirements and the design to achieve this goal requires a lengthy process involving users of different socio-emotional abilities that could be simulated in different context of usage. Drawing conclusions from the data collected will be also difficult in terms of generalisability, similar to research studies. Best practices and guidelines are yet to formulate and evidence of their value is yet to generate. The literature on cyberpsychology is still emerging and studies are mainly focused on the user and their behaviour on digital media rather than the design and its nuances and features (and mostly platformdependent). Each cyberspace exhibits its own instantiation making it hard to assume results are replicable (e.g. the Like's meaning depends on the spirit of the platform and the expectations amongst peers and their norms). In addition, we need measurement tools and ways to establish liability when it comes to assessing the role of design and use in altering the socio-emotion status, and vice versa. Designers' assumptions and decisions can be biased to what they would consider as an average user or a range of possible user models and personas. This can be still a challenge especially when addressing the relationship between socioemotional status and design space variability. As the design and testing process may entail provoking negative emotions in users, ethical concerns might arise.

Designing and testing for inclusivity (considering the variation in users' socio-emotional status) and their inter-relation with the design and its use is a complex question to answer. The main challenge entails the diversity in users' status and the variability in the design, the context of use and their combinations. Overcoming this challenge can benefit from the novel data gathering and adaptive interfaces where artificial intelligence is used to recognise users' emotional status, put smart barriers and protect the needs of users (Churchill, 2020). Such a process can be applied, iteratively, to help designers to optimize their designs through the lived experience and the data captured to respond to the emerging wellbeing requirements. 


\section{REFERENCES}

Abascal, J, and Azevedo, L. (2007). "Fundamentals of Inclusive $\mathrm{HCl}$ Design". In C. Stephanidis (Ed.): Universal Access in $\mathrm{HCl}$, Part I, HCll 2007, LNCS 4554, pp. 3-9, 2007. (C) Springer-Verlag Berlin Heidelberg 2007

Altuwairiqi, M.; Jiang, N.; Ali, R. Problematic Attachment to Social Media: Five Behavioural Archetypes. International Journal Environmental Research And Public Health (2019a), 16, 2136.

Altuwairiqi, M., Arden-Close, E., Bolat, E., Vuillier, L. and Ali, R., (2019b). When People are Problematically Attached to Social Media: How Would the Design Matter?. In Proceedings of IEEE International Conference on Systems, Man, and Cybernetics (IEEE SMC 2019), Bari, Italy

Alutaybi, A.; McAlaney, J.; Arden-Close, E.; Stefanidis, A.; Phalp, K.; Ali, R. Fear of Missing Out (FoMO) as Really Lived: Five Classifications and one Ecology. In Proceedings of the 2019 6th International Conference on Behavioral, Economic and Socio-Cultural Computing (BESC), Beijing, China, 28-30 October 2019; Institute of Electrical and Electronics Engineers (IEEE): Miami, FL, USA, 2019; pp. 1-6

Burklund, L.J., Eisenberger, N.I., \& Lieberman, M.D. (2007). The face of rejection: Rejection sensitivity moderates dorsal anterior cingulate activity to disapproving facial expressions. Social Neuroscience, 2, 238-253.

Calvo, R., Peters, D. (2014) Positive Computing: Technology for Wellbeing and Human Potential. The MIT Press. Cambridge, Massachusetts

Cham, S.; Algashami, A.; Aldhayan, M.; McAlaney, J.; Phalp, K.; Almourad, M.B.; Ali, R. Digital Addiction: Negative Life Experiences and Potential for Technology-Assisted Solutions. Adv. Intell. Syst. Comput. 2019, 16, 921-931.

Churchill, E. (2020). Designing for digital wellbeing. ACM Digital Library. https://interactions.acm.org/archive/view/januaryfebruary-2020/designing-for-digital-well-being

Coleman, R., Lebbon, C., Clarkson, P., and Keates, S. (2003). From margins to mainstream: why inclusive design is better design. In $\mathrm{P}$. Clarkson (Ed.), Inlusive design: Design for the whole population (pp. 1-25). London: Springer

Coyle, D., Linehan, C., Tang, K., Lindley, S. (2012). Interaction design and emotional wellbeing. $\mathrm{CHI}$ 2012, May 5-10, 2012, Austin, TX

Desmet, P., and Pohlmeyer, A. (2013). Positive Design An Introduction to Design for Subjective Well-Being. International Journal of Design. 7, 519

DeWall, C.N., Bushman, B.J. (2011). Social acceptance and rejection: the sweet and the bitter. Current Directions in Psychological Science. 20(4), 256-260
DeWall, C.N., Twenge, J.M., Bushman, B.J., Im, C., \& Williams, K.D. (2010). Acceptance by one differs from acceptance by none: Applying social impact theory to the rejection-aggression link. Social Psychological and Personality Science, 1, 168-174

DeWall, C. N., \& Bushman, B. J. (2011). Social acceptance and rejection: The sweet and the bitter. Current Directions in Psychological Science, 20(4), 256-260.

Dickerson, S.S., \& Kemeny, M.E. (2004). Acute stressors and cortisol responses: A theoretical integration and synthesis of laboratory research. Psychological Bulletin, 130, 355-391

Dickerson, S.S., Gable, S.L., Irwin, M.R., Aziz, N., \& Kemeny, M.E. (2009). Social-evaluative threat and proinflammatory cytokine regulation: An experimental laboratory investigation. Psychological Science, 20, 1237-1244.

Erete, S, Israni, A, Dillahunt, T (2018). "An Intersectional Approach to Designing in the Margins".

Gyi, D.E., Porter, J., Case, K. (2000). Design practice and designing for all. In Human Factors and Ergonomics Society Annual Meeting Proceeding. San Diego, CA, 913-916

Halberstadt, A.G., Denham, S.A., \& Dunsmore, J.C. (2001). Affective social competence, Social Development; 2001, 10, 79 - 119.

Hassenzahl, M (2010) Experience design: Technologu for all the right reasons. Morgan and Claypool Publisher.

Heylighen, A., Bianchin, M. (2013). How does inclusive design relate to good design? Designing as a deliberative enterprise, Design Studies. 34 (1), 93-110

Himmelsbach, J., Schwarz, S., Gerdenitsch, C., Wais-Zechmann, B. \& Tscheligi, M. (2019). Do We Care About Diversity in Human Computer Interaction. A Comprehensive Content Analysis on Diversity Dimensions in Research. In: Proceedings of the $2019 \mathrm{CHI}$ Conference on Human Factors in Computing Systems - $\mathrm{CHI}$ '19.

https://doi.org/https://doi.org/10.1145/3290605.3 300720

Hudson, M. B., Nicolas, S. C., Howser, M. E., Lipsett, K. E., Robinson, I. W., Pope, L. J., Friedman, D. R., et al. (2015). Examining how gender and emoticons influence Facebook jealousy. Cyberpsychol. Behav. Soc. Network. 18, 87-92. doi: 10.1089/cyber.2014.0129

ISO FDIS 9241-210 (2009). Human-centred design process for interactive systems. ISO.

Jirotka, M, Grimpe, B, Stahl, B., Eden, G., Hartswood, M. (2017). Responsible Research and Innovation in the Digital Age. Communications of the ACM. 60, 62-68 
Keates, S., Clarkson, J. (2003) Countering design exclusion-an introduction to inclusive design. Springer, Heidelberg

Widdicks, K., Bates, O., Hazas, M., and Friday, A. (2017). Designing for Digital Wellbeing and its Challenges in Everyday Life. In Proceedings of ACM Conference (Conference'17). ACM, New York, NY, USA, 4 pages. https://doi.org/10.1145/nnnnnnn.nnnnnnn

Leary, M.R. (2010). Affiliation, acceptance, and belonging. In S.T. Fiske, D.T. Gilbert \& G. Lindzey (Eds.), Handbook of Social Psychology (5th Ed., Vol. 2, pp. 864-897). New York, NY: Wiley

Leary, M.R., Kowalski, R.M., Smith, L., \& Phillips, S. (2003). Teasing, rejection, and violence: Case studies of the school shootings. Aggressive Behavior, 29, 202-214.

Löchtefeld, M., Böhmer, M. and Ganev, L., (2013). AppDetox: helping users with mobile app addiction. Proceedings of the 12th International Conference on Mobile and Ubiquitous Multimedia, Luleå, Sweden. Association for Computing Machinery. Article 43.

Luck, R. (2018). Inclusive design and making in practice: Bringing bodily experience into closer contact with making. Design Studies (54). 96-119

Marino, C., Gini, G., Vieno, A., Spada, MM (2018). The associations between problematic Facebook use, psychological distress and well-being among adolescents and young adults: A systematic review and meta-analysis. Journal of Affective Disorder. 15 (226), 274-281. doi: 10.1016/j.jad.2017.10.007. Epub 2017 Oct 3. PMID: 29024900.

Morris, L. (2003). Preface. Inclusive design: design for the whole population. In J. Clarkson, R. Coleman, S. Keates, and C. Lebbon (Eds.). London: Springer-Verlag

Onoda, K., Okamoto, Y., Nakashima, K., Nittono, H., Yoshimura, S., Yamawaki, S., et al. (2010). Does low self-esteem enhance social pain? The relationship between trait self-esteem and anterior cingulate cortex activation induced by ostracism. Social Cognitive \& Affective Neuroscience, 5, 385-391

Parhomenko, K. (2014). Diagnostic Methods of Socio - Emotional Competence in Children. Third annual international conference (Early childhood care and education). Procedia - Social and Behavioral Sciences $146329-333$

Park, S. Y., Kim, S. M., Roh, S., Soh, M.-A., Lee, S. H., Kim, H., Lee, Y. S. and Han, D. H., (2016). The effects of a virtual reality treatment program for online gaming addiction. Computer Methods and Programs in Biomedicine, 129, 99-108.

Perlgut, D. (2011). Digital Inclusion in the Broadband World: Challenges for Australia.? presented at the Communications
Policy and Research Forum, Sydney, November 2011.

Persad, U., Langdon, P., Clarkson, J. (2007). Characterising user capabilities to support inclusive design evaluation. Universal Access in the Information Society. 6, 119-135.

Peters D, Calvo RA and Ryan RM (2018). Designing for Motivation, Engagement and Wellbeing in Digital Experience. Front. Psychol. 9:797. doi: 10.3389/fpsyg.2018.00797

Riva, G., Banos, R., Botella, C., Wiederhold, B., Gaggiolo, A. (2012). Positive Technology: Using Interactive Technology to Promote Positive Functioning. Cyberpsychology, Behavior and Social Networking. 15, 69-77.

Rose, T. (2016). The End of Average: How we Succeed in a World that Values Sameness. San Francisco, CA, HarperOne

Rossetti, R. (2006). The seven principles of universal design. Action Magazine. https://www.udll.com/media-room/articles/theseven-principles-of-universal-design/

Sherman, L. E., Payton, A. A., Hernandez, L. M., Greenfield, P. M., \& Dapretto, M. (2016). The power of the like in adolescence: Effects of peer influence on neural and behavioral responses to social media. Psychological science, 27(7), 1027-1035.

Verbeek, P. P. (2005). What things do: Philosophical reflections on technology, agency, and design. (R. P. Crease, Trans.). University Park, PA: Penn State Press.

Vorderer, P., \& Schneider, F. M. (2017). Social media and ostracism. Ostracism, exclusion, and rejection, 240-257.

Williams, K.D., Cheung, C.K.T., \& Choi, W. (2000). Cyberostracism: Effects of being ignored over the Internet. Journal of Personality and Social Psychology, 79, 748-762

Wright E.J., White, K.M., Obst, P.L (2018). Facebook False Self-Presentation Behaviors and Negative Mental Health. Cyberpsychology Behaviour and Social Networking. 21(1), 40-49. doi: 10.1089/cyber.2016.0647. 